\title{
Social Acceleration Theory and the Self
}

\section{ERIC L. HSU AND ANTHONY ELLIOTT}

\author{
ABSTRACT
}

In recent years, there has been a rapidly growing body of work in the social sciences that underscores the prevalence of the phenomenon of 'social acceleration' - the speeding up of social life - in many parts of the Western world. Although research on social acceleration has tended to analyze the phenomenon on a social-structural level, there is also a need to investigate how social acceleration has 'ramifications for the socially dominant forms of self-relation'. One way to gain a more in-depth understanding of this facet of social acceleration is to investigate the speeding up of social life through the prism of the self. The central argument of this article is that there are at least five images of the self which can be associated with the social acceleration phenomenon: (1) the 'detached' self, (2) the 'reflexive' self, (3) the 'reinventive' self, (4) the 'stationary' self and (5) the 'decelerating' self. By explaining how these kinds of self relate to the speeding up process, we seek to advance a more nuanced and sophisticated theory of social acceleration, which captures some of the complexities and paradoxes that the phenomenon involves.

Keywords: Social acceleration, speed, self, deceleration, modernity, dialogical, time

\section{INTRODUCTION}

In recent years, there has been a rapidly growing body of work in the social sciences that explores the phenomenon of 'social acceleration', the speeding up of social life. Numerous studies have described how seemingly prevalent this phenomenon has become in many parts of the Western world (e.g. Bertman, 1998; Agger, 2004; Eriksen, 2001; St. Clair, 2011). Recent scholarly work in the social sciences has observed how much of this literature around social acceleration has lacked a solid empirical basis and thus has been overly based on conjecture and hyperbole (Wajcman, 2008; Rosa \& Scheuerman, 2009). Some scholars have also suggested that the social acceleration debate is in need of more sophisticated 
ways of theorizing the social acceleration concept (Hassan, 2010; Hsu 2014b), since the notion has not been explicitly defined or adequately described in many instances.

The work of Hartmut Rosa (2003, 2010a, 2010b, 2013) is an important exception; his research has done much to address this latter shortcoming of the social acceleration literature. ${ }^{1}$ By proposing a tripartite model of the social acceleration process, Rosa has persuasively argued for a theory of social acceleration that is empirically verifiable and more complexly conceptualized. This crucially involves the recognition that social acceleration is a multi-faceted process which bears upon a multitude of levels of social life. Hence, social acceleration can express itself through the speeding up 'of society as a whole' (Rosa, 2003, p. 7), just as it can have 'ramifications for the socially dominant forms of self-relation' (Rosa, 2013, p. 224).

To help further advance such a dynamic understanding of the social acceleration phenomenon, we seek in this article to provide a novel and detailed theoretical account of how the speeding up of social life has a personal impact and component. As we aim to show in the following section, the social acceleration debate has tended to analyze the phenomenon on a macro social-structural level. Yet, relatively less is known about the micro-elements of social acceleration, which describe how the speeding up of social life leads to, but also is enabled by, 'marked changes in personality and character' (Bertman, 1998, p. 46).

One way to gain a more in-depth understanding of this facet of social acceleration is to investigate the speeding up of social life through the prism of the self. In recent years, the concept of the self has come to enjoy wide circulation in a number of disciplines in the social sciences, such as in sociology (Elliott, 2014), geography (Pile, 1993) and social psychology (Baumeister, 1999). However, definitions of the self are manifold and usages of the term within and between disciplines have not tended to be consistent or wholly unified. ${ }^{2}$ It is beyond the purview of this article to resolve these definitional and conceptual discrepancies. And indeed, we make no claim that our understanding of the self in this article encapsulates or has bearing upon the myriad of ways it has been theorized in the broader literature.

The concept of the self that we operate with here is informed by Timothy Owens's sociologically-minded definition of the self as 'an organized and interactive system of thoughts, feelings, identities, and motives that (1) is born of self-reflexivity and language, (2) [that] people attribute to themselves, and (3) [that] characterize specific human beings' (2003, p. 206, emphasis in original). One of the most insightful aspects of Owens's account is that it frames the self as both a 'social product' and a 'social force' (2003, pp. 209-210). The self is a 'social product' because it is to some extent 'a social creation, molded by a person's interactions with others, his or her past and ongoing affiliations and experiences within and across social contexts and institutional affiliations, and his or her location within culture and social structure' (Owens, 2003, p. 209). But the self is also a 'social force' in that it can 'influence 
the groups to which a person belongs as well as the society as a whole' (Owens, 2003, p. 210). ${ }^{3}$ If concept of the self is understood in these ways, then it thus becomes possible to investigate how social acceleration affects people on a personal level. But equally, it also becomes possible to explore how social acceleration itself is partly an outcome of certain psychological changes.

The aim of this article therefore is to articulate how social acceleration affectsand also is affected by - people's sense of selfhood in a variety of different ways. The central argument of this article is that there are at least five images of the self which can be associated with the social acceleration phenomenon: (1) the 'detached' self, (2) the 'reflexive' self, (3) the 'reinventive' self, (4) the 'stationary' self and (5) the 'decelerating' self. By explaining how these kinds of self are involved with the speeding up of social life, we primarily seek to further advance a more nuanced and sophisticated theory of social acceleration, which critically involves multi-faceted explanations of its drivers and consequences (Rosa, 2013).

\section{OVERVIEW OF THE SOCIAL ACGELERATION DEBATE}

According to Hartmut Rosa and William Scheuerman, 'acceleration figures as a striking feature of prominent diagnoses of contemporary social development' (2009, p. 2, emphasis in original). Indeed, there is now an extensive body of literature that uses the optic of speed to make sense of various aspects of the contemporary social world (e.g. Tomlinson, 2007; Vostal, 2014; Agger, 2004; Hassan, 2009; Eriksen, 2001; Elliott et al., 2012). Speed has recently become a more prominent issue because of the heightened realization that 'the manner of our being-in-the-world depends to a great degree on the temporal structures (Zeitstrukturen) of the society in which we live' (Rosa, 2013, p. xxxviii, emphasis in original). ${ }^{4}$

As a way of moving the social acceleration debate forward, some scholars have sought to advance more sophisticated and nuanced theoretical understandings of social acceleration (Rosa, 2003, 2013; Rosa \& Scheuerman, 2009; Hsu, 2014b; Vostal, 2014). This has crucially involved the recognition that the speeding up of social life is not a singular process. Rosa's account of social acceleration has been especially influential in articulating this way of thinking. What is unique and insightful about Rosa's theory of social acceleration is that it identifies how social acceleration operates and manifests itself in three distinct forms. 'Technological acceleration', the first form of social acceleration in Rosa's account, refers to when there is a reduction in the amount of time it takes for 'goal-oriented' and 'intentional' processes, like that of 'transport, communication and production', to reach completion (Rosa, 2003, p. 6). The second form of social acceleration identified by Rosa, the 'acceleration of the pace of life', refers to the heightened scarcity of 'free' time which paradoxically ${ }^{5}$ occurs when there is a reduction in the amount of time needed to complete social processes (2003, pp. 8-10). And lastly, the third form of 
social acceleration that Rosa proposes, the 'acceleration of society as a whole', refers to when a society's rate of change quickens so that there is a 'contraction' in amount of time it usually takes for social change to occur (2003, p. 7).

One of the upshots of Rosa's tripartite account of social acceleration is that it reveals some of complexities that the social acceleration phenomenon involves. For example, the third form of social acceleration identified by Rosa suggests that social acceleration does not just effect change within society as the first two forms indicate, since the speeding up of society also signals a change in the rate of change itself. ${ }^{6}$ Rosa's account of social acceleration (2013, pp. 151-207) also underscores how the phenomenon is driven by a myriad of different factors. Not only is social acceleration to some extent 'a self-propelling process' (2013, p. 151, emphasis in original), Rosa suggests that there are at least four other 'external' driving forces at work. ${ }^{7}$

Such multifaceted ways of understanding social acceleration have helped to move the social acceleration debate forward. But so too has the study of social acceleration been advanced by scholarly work which has investigated the ways in which social acceleration is present in a multitude of social realms and contexts. For example, a number of scholars have used social acceleration to explain recent changes to the capitalist system. What principally distinguishes how capitalism operates in the present day from other time periods is said to be the acceleration of its processes (e.g. Agger, 2004; Luttwak, 1999; Hutton \& Giddens, 2001). This is evident in the promotion of 'high speed' corporate management styles (e.g. King \& Cushman 1994; Cordero, 1991) and in the way production, consumption and employment strategies within many industries have become more 'shortterm' oriented (e.g. Toffler, 1970; Luttwak, 1999; Agger, 2004). ${ }^{8}$

Many texts have also sought to illustrate how social acceleration profoundly affects the practice of liberal democracy, as 'many traditional notions about liberal democracy rest on assumptions about temporality which become increasingly problematic with the heightened pace of social life' (Scheuerman, 2004, p. xiii). With the 'motorization' of the legislative process (Schmitt, 2009) and the elevation of speed as 'a top-ranking concern' in the field of politics (Chesneaux, 2000, p. 409), the liberal democratic ideal of deliberation - which usually requires a considerable amount of time and reflection - figures to be of decreasing importance. And hence, this helps to explain why the executive branch of government has recently grown more powerful in many countries (Scheuerman, 2004; Jessop, 2005) and why some of the time-consuming demands of democratic citizenship no longer seem as feasible as they once did (Scheuerman, 2005). ${ }^{9}$

In debates about contemporary society, social acceleration has also been connected to recent developments in communications and transport. Social acceleration is said to be partly responsible for the proliferation of faster and more extensive communication and transit systems (Jensen, 2006; Eriksen, 2001; Heylighen, 1998). What David Harvey's concept of 'time-space compression' (1999) reveals is that the 'overcoming of spatial barriers' is somehow related to and 
informed by 'the shortening of time horizons' (Allen \& Hamnett, 1995, p. 9) and thus, time-space compression has been commonly been used to associate new communication and transport practices with the advancement of high speed lifestyles.

Additionally, social acceleration has been linked to recent changes in the way people conduct their family lives. Some scholars, for example, have sought to show how social acceleration transforms how children are raised, as children are no longer allowed to be 'time rebels' and are instead 'expected to live up to adultlike standards of production and performance' (Agger \& Shelton, 2007, p. 76; see also Bertman, 1998, pp. 70-78). Social acceleration has also played a significant role in the analysis of how people form intimate relationships with one another. Some studies suggest that love relationships are no longer thought to be as geared for the long term as they once were (Bertman, 1998, pp. 66-68; see also Bauman, 2003).

\section{SOCIAL ACCELERATION THROUGH THE PRISM OF SELFHOOD}

In these and other accounts of social acceleration, what is commonly foregrounded is the way in which social acceleration operates at the sociostructural level. However, it is further important to recognize that social acceleration also has psychological, affective and emotional dimensions, as some have recently sought to show (Bertman, 1998; Tomlinson, 2007; Rosa \& Scheuerman, 2009; Rosa, 2013). Not only does social acceleration change 'our relationship 'toward space and time, the natural and material structures surrounding us (the objective world), [and] toward our fellow human beings (the social world)', but also it influences how we relate to ourselves in 'the subjective world' (Rosa \& Scheuerman, 2009, pp. 16-17).

The aim of this article is to augment what we know about this particular aspect of social acceleration through the prism of the self. The self, according to some formulations, is at its core a temporal phenomenon (Flaherty \& Fine, 2001; Cross \& Gore, 2005). Since the 'self emerges from the dynamic interplay of present, past, and future' (Flaherty \& Fine, 2001, p. 157), this indicates that the concept of self fundamentally describes a temporal process. But it is also possible to use the self to mark shifts in the broader socio-temporal order, as the self is to some degree a 'malleable' or 'plastic' entity, which is informed by - and informing of - its surrounding social and cultural conditions (e.g. Heine, 2001; Stetsenko \& Arievitch, 2004). The self is 'malleable' or 'plastic' in the sense that new variants and forms of it can emerge against the backdrop of broader social changes. And hence, this is why a number of scholars working in the fields of sociology and social psychology have posited that certain types of self, such as the 'multiphrenic' self (Gergen, 1991), the 'protean' self (Lifton, 1999), and the 'tethered' self (Turkle, 2008), have either newly emerged or become more prominent 
as various technological, economic and/or cultural transformations within society have taken place.

In similar vein, we seek in this article to describe a number of types of self that have arisen, which can be linked to the speeding up process. Through a detailed discussion of what each of these selves entails, our goal here is to expand what we know about the various psychological drivers and consequences of social acceleration. Consequently, this is meant to further advance a more sophisticated and dynamic theoretical understanding of social acceleration, which captures some of the complexities and paradoxes that the phenomenon involves.

\section{THE DETACHED SELF}

The feeling of detachment is what characterizes the first type of self that we associate with the speeding up of social life. Why social acceleration is linked to such a 'detached' mode of being is because people living in high-speed societies routinely encounter objects, social arrangements, technologies, experiences and types of people, which tend to be new or updated (Rosa, 2003, pp. 7-8; Toffler, 1970). This commonly leads to a hyper-stimulated and frenzied lifestyle, which in turn, according to the work of Georg Simmel, (2002), paradoxically engenders a 'blasé attitude'. People adopt a 'blasé attitude' when they are exposed to such high levels of social change that they become incapable of reacting 'to new stimulations with the required amount of energy' (Simmel, 2004, p. 14).

Consequently, we posit that all of this has implications for a person's sense of self. As people are encouraged to become more indifferent 'toward the distinctions between things' (Simmel, 2002, p. 14), the self in these circumstances becomes more willing to accept routine changes to a person's personality and character. Selfhood then becomes accustomed to the regularity of change, such that selftransformation becomes a mundane practice. The detached self thus comes to the fore when individuals become less sensitive and concerned about the shifts that are taking place in and around them.

Because the detached self fosters a deep sense of indifference towards the changing contents of the world, this is therefore why it facilitates the drive to accelerate the pace of social life. The detached self signals when people become so resigned to the logics of a high-speed society that social acceleration is experienced as a 'stream which scarcely requires any individual efforts for its ongoing' (Simmel, 2002, p. 19). The detached self, in other words, becomes pronounced when individuals passively accept that perpetual change is a regular feature of the world in which they live.

Yet, for Simmel, the indifference that results from the blasé attitude is also what encourages people to 'turn to more excessive, adventurous, and risky behavior[s]' (Aho, 2007, p. 448). As novelty becomes routinized (Thiele, 1997), people begin to seek out 'more intense, risky, and excessive experiences that will spark, albeit 
briefly, some sort of strong emotional reaction' (Aho, 2007, p. 455). This 'search for momentary satisfaction in ever new stimulations, sensations, and external activities' (Simmel, 2004, p. 490) is what then propels the social acceleration process even farther forward. Because 'yesterday's pleasures become boring and uninteresting' (Aho, 2007, p. 457), people become even more willing to seek out what is new, thereby accelerating the pace of social change as a whole. What the detached self therefore describes is how social acceleration can come to be accepted as an ordinary fact of everyday life, which then potentially leads to further bouts of acceleration.

THE REFLEXIVE SELF

The second type of self we associate with the speeding up of social life, the reflexive self, puts more of an emphasis on the self-directing qualities of social acceleration. In contrast to the detached self which highlights how people passively accept the logics of a high-speed society, the reflexive self occurs when social acceleration partly emerges as a consequence of the decisions that individuals make to alter the course of their lives. What the reflexive self is meant to describe then is the way in which people exert a degree of control over the social acceleration process.

As Hartmut Rosa postulates, one of the key drivers of social acceleration - and also what makes people feel like they are the agents of speed-has to do with 'the dominant cultural ideals of modernity' (2003, p. 13). ${ }^{10}$ Rosa focuses especially on 'the modern concept of freedom as self-determination', which defines the 'good life' as being 'autonomous' and 'free from external brakes, obstacles, shortages and hindrances' (2010a). In order to live the 'good life', Rosa suggests that the social order needs to be sufficiently 'fluid' and open-ended (2010a). This implies a greater willingness to break free from tradition, which according to a number of authors is what principally defines the modern project (Giddens, 1990, 1991; Beck, 1994). ${ }^{11}$

In Anthony Giddens's account of modernity, it is ' heightened reflexive selfawareness' which in particular 'provides the individual with the opportunity to construct self-identity without the shackles of tradition and culture' (Adams, 2003, pp. 221-222). Reflexivity for Giddens is a property of all human agency. But in conditions of advanced modernity, the reflexivity of the self is radicalized. The 'reflexivity of modernity', which 'refers to the susceptibility of most aspects of social activity, and material relations with nature, to chronic revision in light of new information or knowledge' (Giddens, 1991, p. 20), is something that 'extends into the core of the self' (Giddens, 1991, p. 32). In conditions of reflexive modernity, according to Giddens, individuals 'have no choice but to choose how to be and how to act' (1994, p. 75). Consequently, the 'more individuals are forced to negotiate lifestyle choices among a diversity of options', then the 'more tradition 
loses it hold' (Giddens, 1991, p. 5). And this in turn brings about a more openended understanding of the future, as people come to believe that fate is not all that pre-determined (Giddens, 1991, pp. 109-114).

This reflexive form of modern self-making, as Rosa (2010a) notes, is also what drives the 'acceleration of the rates of change'. When the past no longer strongly limits how the self is constituted, social change tends to happen more quickly and more frequently. And thus, this highlights how social acceleration can be used to help people change the trajectory of their own lives. Hence, what the reflexive self reveals is how people are not merely 'hapless victims of socially caused acceleration', as social acceleration can be strategically deployed to serve other aims (Rosa, 2010a).

However, the reflexive self not only describes how people can steer the social acceleration process, since such attempts can sometimes lead to unwelcome and/or unexpected consequences. This has to do with the intrinsic dynamism of modern reflexivity, which oscillates between feelings of autonomy and powerlessness (Giddens, 1991, pp. 191-194). As Giddens suggests, living in the modern world is like riding a juggernaut, which 'we can drive to some extent but which also threatens to rush out of our control' (1990, p. 139). And so too is this the case with social acceleration in modern settings. While the modern drive to accelerate the pace of life can be 'represented justified, and experienced as a necessary aspect of the bending of nature. . . to human design', modern speed also has the capacity to become 'unruly' (Tomlinson, 2007, p. 44). The experience of modern speed can be unsettling and socially disruptive because there is always a part of it that 'escapes discipline and regulation' (Tomlinson, 2007, p. 9). The faster social life becomes past a certain threshold, the more people struggle to keep pace. This may be because there are 'limits to the amount of change that the human organism can absorb' (Toffler, 1970, p. 326; see also St. Clair, 2011, pp. 70-75). When social acceleration becomes extremely pronounced in a given society, then people usually have less time to determine what is the best course of action to take. And consequently, 'the less slow time that remains to think decisions through, . . the greater the risk for disastrous errors' (Eriksen, 2001, p. 65). ${ }^{12}$

But even though social acceleration is capable of defying expectations and social commands, John Tomlinson (2007) notes how efforts can still be made to limit the fallout of 'unruly' bouts of social acceleration. Because 'the impulse to promote speed in one area of life begets the need to regulate, even to suppress it, in others' (Tomlinson, 2007, p. 65), this means that the disciplinary side of social acceleration is, to some extent, tied to the transgressive impulses that the phenomenon provokes. ${ }^{13}$ Social acceleration then is not a wholly uncontrollable process, just as it is not completely amenable to regulation.

And correspondingly, this is what the reflexive self is meant to capture about acceleration in the modern world. The reflexive self describes when social acceleration is used to facilitate a more open-ended - and therefore, autonomousapproach to self-making in modern settings. However, because there is always 
something 'unruly' about social acceleration, the steering of social acceleration towards favored and anticipated ends is only ever partially and provisionally successful, and thus it must be an ongoing process.

\section{THE REINVENTIVE SELF}

One of the analytical shortcomings of associating the reflexive self with the speeding up of social life is that reflexivity may not fully capture how dislocating social acceleration can be at the level of lived experience. This is because the reflexive self merely hints at the risks and dangers that are involved with living in a high-speed society. We find that the reinventive self, by contrast, is better able to spell out how destabilizing social acceleration can be to the character and identity of persons.

Recently, some social researchers have used the idiom of 'reinvention' to explain changes in a variety of social contexts (e.g. Thrift, 2006, 2008; Erturk \& Solari, 2007; Elliott, 2008, 2013; Nyseth \& Viken, 2009). For instance, Nigel Thrift $(2006,2008)$ has argued that the phenomenon of 're-inventing invention' is an increasingly significant force - at once cultural and institutional - in the global economy; innovation, recast through the lens of reinvention, now shapes cultural expectations as to what constitutes a 'successful business' in many parts of the contemporary Western world. This refers to Thrift's observation that 'a new resource based around the capacity for inventiveness' has come to the fore in the 'current trajectory of capitalism' (2008, p. 115). In order to respond to the increased pressure 'to improve their rate of inventiveness' (2008, p. 120), companies are starting to place a strong premium on workers who are able to reinvent themselves as well as the organizations they work for. The culture of reinvention for Thrift is one of radical self-experimentation, self-transformation and self-reorganization.

Torill Nyseth (2009) suggests that this perpetual need for reinvention also has bearing on the way some Northern European cities and towns develop. Places in Northern Europe, according to Nyseth, are not merely being 're-branded', as some have thought (2009, pp. 2-3). Rather, places are being 'reinvented', as they seek to become more 'experimental, innovative, fluid and dynamic' to adapt to the ever-changing global context (Nyseth, 2009, p. 3).

There are however a number of downsides associated with the rise of a reinvention culture. Ismail Erturk and Stefano Solari (2007), for instance, express concern over the continuous re-invention of US and European banks in recent decades. They suggest that the incessant impulse to reinvent banking practices has led to riskier and more unstable market conditions.

The work of Anthony Elliott $(2008,2013)$ also underscores the social and emotional costs of a culture held in thrall to perpetual reinvention. Elliott, in particular, has focused on how reinvention culture transforms people's sense of identity. A central idea proposed by Elliott is that even though reinvention is 'an 
experiment with possible versions of the self' which can be 'freeing', 'it can however also be disabling, and even pathological' (2013, p. 93). At the core of Elliott's critique of what he terms 'reinvention society' is the pace at which reinvention projects now occur, unfold and interweave with trajectories of the self (2013, p. 95). When people are expected to reinvent themselves in a high-speed society, they run the risk of being overwhelmed by the speed at which changes are meant to take place.

According to Elliott, social acceleration has the capacity to significantly alter the experience of reinvention, so that it does more than cause certain parts of one's identity to be called into question from time to time. Rather, when reinvention becomes so accelerated that it becomes ceaseless 'day-in, day out', the concept of identity itself for Elliott 'becomes disposable', especially if the concept implies a center or fixed point of origin (2008, pp. 126-127). This, then, can partly explain why a number of psychical maladies and emotional troubles have become more pronounced. What the speeding up of social life has the potential to bring about through the practice of reinvention is a mode of being that is in some ways significantly open-ended. The emergence of a self that can be endlessly re-fashioned, however, also ironically entails a heightened sense of anxiety about having to make frenetic choices on a regular basis, which can be psychologically debilitating in some circumstances (2008, p. 126).

Perhaps more concerning though is that the acceleration of reinvention may also lead to the 'obliteration of value and meaning' for the individual (Elliott, 2013, p. 6). This has to do with one of the central dilemmas that individuals face in the contemporary modern era: 'how to be flexible enough to survive high levels of personal and cultural drift without being left drained of identity' (Elliott, 2008, p. 122). Elliott suggests that this dilemma is especially applicable to the growing popularity of cosmetic surgery in many parts of the Western world. In a 'fastflowing' society, Elliott finds that 'surgical enhancements of the body are primarily undertaken with the short term in mind', as they are commonly only good 'until the next procedure' (Elliott, 2008, p. 91). Accordingly, some people run the risk of getting caught in a 'brutally despairing circle', where the 'consumption of cosmetic surgery appears incapable of [ever] coming to an end' (Elliott, 2008, p. 91). This happens when 'the desire to remake selfhood becomes semi-autonomous', with 'the very act of surgical enhancement body parts becoming the object of desire in itself' (Elliott, 2008, p. 91). In turn, what this is meant to signal is the way in which social acceleration can alter the aims and effects of reinvention, so that the practice no longer empowers those who engage in it.

What the rise of a reinventive self thus calls attention to - which is partly overlooked by the reflexive self - is the extent to which social acceleration can dramatically re-orient people's sense of whom or what they are. The reinventive self reveals that the social acceleration phenomenon does more than prompt sporadic modifications to one's identity, since the phenomenon has the capacity to press the concept of identity itself to its very limits. 
The fourth type of self we associate with the social acceleration phenomenon, the stationary self, may seem puzzling because at first glance it appears to call into question the existence of the phenomenon altogether. At the core of the stationary self is the perception that 'nothing essential changes anymore' and that 'nothing new occurs' (Rosa, 2013, p. 15). Rosa identifies a number of places where this view has found expression in recent times. For instance, Rosa finds that Francis Fukuyama's 'end of history' thesis (1992) has voiced — although not uniquely - the idea that ' "real' change is in fact no longer possible' in the contemporary era (Rosa, 2003, pp. 16-17). Other social thinkers and scholars from a variety of different standpoints have also come to the conclusion that the contemporary social world lacks the capacity to be transformed in a meaningful way (e.g. Offe, 1987; Kavanagh et al., 2007; Savage, 2009).

However, while it is tempting to think that this line of thought directly contradicts the social acceleration argument, Rosa (2013) argues that we ought to think of the two as being complementary to one another. This is because the more pronounced social acceleration becomes in all facets of social life, the more fixed and unalterable it also appears. In other words, social acceleration prompts people to perceive that social change is no longer possible because of the constancy of the accelerative process. Rosa (2013, p. 15) invokes the concept of 'frenetic standstill' - which derives from an 'inspired' German translation of Paul Virilio's term, 'polar inertia' - to illustrate this peculiar feature of social acceleration. What frenetic standstill is able to capture is how social acceleration alters the way a society reproduces itself, so that becoming faster no longer leads to significant social transformations. Rather, the speeding up of social life is mainly used to keep things as they are, which is why the metaphor of the 'treadmill' potently describes what life can be like in a high-speed society (Rosa, 2010).

Rosa suggests that the experience of frenetic standstill has a number of psychological consequences. One in particular is that the 'biographical course of life as a whole loses its direction (Rosa, 2013, p. 246, emphasis in original). Because social acceleration can lead to a shortage of 'stable perspectives that organize time', life can seem 'like an aimless drift through changing situations' (Rosa, 2013, p. 247). Depression, for Rosa (2013, p. 248), is the purest pathological embodiment of this temporal experience. For those who are affected by the condition, 'time no longer seems to move, but to stand absolutely still' (Rosa, 2010). Consequently, this futureless sense of time is what renders the depressed person incapable of directing sufficient 'energy towards a fixed, constant, subjectively worthwhile goal' (Rosa, 2013, p. 249, emphasis in original). If the 'collapse of a past or future horizon' is one of the paradoxical features of the social acceleration phenomenon as Rosa suggests (2013, p. 17), then this can help to explain why depression has become more of a 'structurally inescapable universal experience' in high-speed societies (2013, p. 249). 
By associating the experience of time standing still with the speeding up of social life, Rosa therefore accounts for why the self can become a stationary entity during periods of intense social acceleration. The stationary self has the capacity to co-exist with the other types of self outlined in this paper because of the inherently paradoxical nature of the social acceleration process. Not only does social acceleration lead to the intensification of social change, but also it leads to the rigidification of social structures (Rosa, 2013, p. 89). Hence, this is why social acceleration, at the level of the self, 'constantly threatens to flip over from a stimulating "heightening of sensory life" [...] into its opposite, namely, the experience of an eventless, existential tedium (l'ennul' (Rosa, 2013, p. 284). In extreme cases when selfhood becomes stationary, time may come to such a standstill that depressive ailments become more prevalent.

\section{THE DECELERATING SELF}

As with the stationary self, it may initially seem counter-intuitive to associate the fifth and final type of self, the decelerating self, with the speeding up of social life. This is because the decelerating self also does not appear to facilitate the social acceleration phenomenon. However, what is distinctive about the decelerating self is that it may represent, to some degree, an external force that counteracts the accelerative process. Whereas the stationary self can be conceptualized as an internal element of social acceleration, the decelerating self can challenge the very logics of a high-speed society.

Why it is important to draw a link between social acceleration and the decelerating self is because social acceleration is almost never a totalizing phenomenon. If we do not consider how the speeding up of social life relates to the phenomenon of social deceleration, then we get an overly one-sided temporal diagnosis of the social world (Rosa \& Scheuerman, 2009, pp. 4-5). Thus in order to arrive at a more balanced theory of social acceleration, we need to appreciate the resistances and countertrends which normally accompany bouts of acceleration (Rosa, 2003, pp. 14-17, 2013). This involves the recognition that there are some types of self which conflict with faster ways of living, just as there are those that seek to facilitate high-speed lifestyles.

A unique feature of the decelerating self is that it can arise either intentionally or inadvertently (Rosa, 2013, pp. 84-86). When selfhood is purposefully meant to slow down the pace of life, then this can in some cases bring about a genuine transformation in the socio-temporal order. This is evident, for example, in the type of self which has been espoused by the global slow food movement. Through its various practices and cultural philosophies, the slow food movement has sought to promote a self that is more 'carefully' and 'mindfully' cultivated (Tam, 2008). The development of such an approach to selfhood has consequently been construed as a way for people to resist the dominant ideals of a high-speed society (Parkins, 2004; Parkins \& Craig, 2006). 
Not all social decelerations however are intentionally generated, since there are some that may occur as an 'unintended consequence of processes of acceleration and dynamization' (Rosa, 2010b, p. 35, emphasis in original). ${ }^{14}$ At the level of selfhood, this means that there are some modes of being which may counteract the social acceleration process, even though their aim is to do the opposite. This is evident, for example, in the advancement of increasingly 'incessant' lifestyles, which attempt to augment the amount of things people are able to accomplish by curtailing how much time people spend in states of sleep or rest (Melbin, 1987; see also Crary, 2013). Although it may seem logical to think that a self which tries to be more continuously active might further along the social acceleration process, there is cause to think that such a type of self may lead to opposite outcomes. This relates to the growing cultural and medical discourse around the dangers of sleep deprivation (Williams, 2005, pp. 104-105). Sleep, from this perspective, is increasingly framed as a 'vital and valuable preparation for (rather than simply the unfortunate, inevitable and inescapable by-product of) everyday waking roles and working life' (Williams, 2011, pp. 35-36). Efforts to depreciate sleep can cause people to be less competent in multitude of ways and hence they can be quite counterproductive (Hsu, 2014b). Therefore when selfhood becomes more incessant, the pace of social life might unintentionally become slower instead of faster.

Besides being either inadvertently or deliberately caused, one other aspect of the decelerating self which needs to be considered is that the decelerating self does not always stand opposed to the acceleration of social life. This is because there are, according to Rosa, 'temporary forms of deceleration which aim at preserving the capacity to function and [to] further accelerate within acceleratory systems' (2010b, p. 36), such as when individuals take part in yoga-courses to cope with 'the swift-paced life of the workplace, relationships, or everyday routine even more successfully' (2013, p. 87). Accordingly, there is the possibility that the ideal form of self endorsed by the slow food movement might also function as one of these 'accelerative slowdowns'. And thus, it may be worthwhile to consider how this type of self seeks to facilitate further social accelerations, just as it is prudent to consider how this type of self represents a genuine departure from faster ways of living. ${ }^{15}$

The decelerating self, in sum, speaks to the partial and discontinuous nature of the social acceleration process. If we are to avoid overstating the reach and impact that social acceleration has on a given society, then it is important to understand how there are some types of self which emerge either purposefully or unintentionally to interfere with accelerations of social life. For a more nuanced understanding of the decelerating self, it is also important to understand how some slowdowns might actually enable further accelerations down the track.

ON THE INTRICACIES AND IMPLICATIONS OF SOCIAL ACCELERATION THEORY

Since the main purpose of this article has been to advance a more sophisticated and complex theoretical understanding of social acceleration, our multifaceted 
account of how social acceleration is experienced at the level of the self will likely be of most relevance to those engaged in the sociological study of social acceleration. As a number of recent sociological studies of social acceleration have shown (Simonsen, 2005; Rosa, 2013; Rosa \& Scheuerman, 2009; Hsu, 2014b), the speeding up of social life involves a number of paradoxes, complexities and discontinuities - many of which have not always been adequately recognized or described. In this article, we have established that some of these paradoxes, complexities and discontinuities associated with social acceleration can be uniquely captured through the prism of selfhood. ${ }^{16}$

One underemphasized aspect of the social acceleration concept that we have sought to further illuminate is the way in which the phenomenon is marked by both feelings of indifference and excitement (Simmel, 2002; Aho, 2007), as revealed by our description of the 'detached' self. This type of self principally helps to explain why people can become so resigned to the logics of a high-speed society. Through our discussion of the 'reflexive' self, we have also sought to highlight how the experience of social acceleration is driven by feelings of autonomy, since speed is involved in the modern advancement of a post-traditional social order (Rosa, 2010a). Yet at the same time, we have also emphasized how social acceleration is an unruly phenomenon that to some extent defies social control (Tomlinson, 2007). The dislocating quality of social acceleration is especially evident in the case of the 'reinventive' self, which shows how social acceleration affects various social practices so that they no longer empower those who engage in them (Elliott, 2008, 2013). Another facet of the social acceleration process that this article underscores concerns the paradoxical capacity of social acceleration to elicit feelings of paralysis, while also intensifying the experience of movement at the same time (Rosa, 2013). By using the prism of the 'stationary' self, we describe how the perceived rigidification of social identity can actually arise as an outcrop of efforts to speed up the pace of social life, which thus explains why depression might become a more prevalent experience in high-speed environments. Finally, we have in this article further substantiated the claim for a more discontinuous and less totalizing understanding of social acceleration (Hsu, 2014b) through our discussion of the 'decelerating' self. One facet of the decelerating self is that it arises either purposefully or inadvertently to counteract swift-paced lifestyles. But another facet of the decelerating self is that it can lead to further future accelerations by helping individuals to cope with the demands of a high-speed society (Rosa, 2013).

In formulating this theoretical account of social acceleration which involves these five types of self, we make no claim however about how pronounced each type of self has become in comparison to others. It is likely that such versions of the self cross and tangle in complex, contradictory ways; and this is clearly a matter for further sociological reflection and research. Furthermore, it is also beyond the purview of this article to posit the broader social consequences carried by these types of self. Social acceleration, as some have noted, is 'a multilateral and 
ambivalent social phenomenon' that has both enabling and detrimental features (Vostal, 2014, p. 96). To properly assess the various impacts that social acceleration has, it is necessary therefore to understand the social context in which it is situated (Hsu, 2014b). Hence, in order to analyze the affect and significance that the speeding up of social life has on a particular society, further empirical sociological research is duly needed (Wajcman, 2008).

However, although our theorization of social acceleration has not directly engaged with how the self has been analyzed in the field of social psychology, our account of social acceleration nonetheless may have some capacity to tangentially inform how the self is theorized within that area of study. While there is indeed a fair amount of literature focused on the general social psychological experience of time (e.g. McGrath \& Kelly, 1986; Levine, 1997), there is still according to Alex Szollos 'a paucity of empirical research within the discipline on time shortage and the accelerating pace of living, as if these experiences were treated as epiphenomena and not problems in their own right' (2009, p. 335). One way to develop a psychological account of social acceleration is to investigate how the experience of the self varies according to shifts in the socio-temporal order, which is what our article has chiefly sought to illuminate.

But it is also possible to further develop a psychological account of social acceleration by exploring how the phenomenon influences the ways in which the self is conceptualized from a social psychological perspective. One of the major theoretical advances in the social psychology of the self has been the adoption and refinement of a 'dialogical' approach to understanding selfhood (e.g. Salgado \& Goncalves, 2007; Grossen \& Salazar Orvig, 2011). Dialogical approaches to the self have stressed that the self is a heterogeneous and dynamic entity by describing how the self consists of a number of dualities. One of these dualities is that the self is not only continually open to change and transformation but also to some degree a 'stable' and enduring entity (Salgado \& Goncalves, 2007, pp. 615-616; Grossen \& Orvig, 2011; Moore et al., 2011). Recently, there has been a concerted effort made by some scholars to develop a more in-depth understanding of how the self maintains a certain level of stability (e.g. Grossen \& Salazar Orvig, 2011; Moore et al., 2011). The self is not simply 'adrift on a sea of ever-changing interactions, reborn anew in each interaction' (Moore et al. 2011, p. 511), because the shared material conditions and social routines and institutions in people's lives all 'contribute to constructing the stability of the self and the subject's experience of "being the same", (Grossen \& Salazar Orvig, 2011, p. 505). According to Helen Moore et al. (2011), the stability and instability of the self also has much to do with the concept of frames. When a person's activity stays within a given frame of guided action, the self tends to become more stable, whereas 'being caught between [...] frames has the opposite effect, becoming a source of dialogical tension' (Moore et al., 2011, p. 517). 
Our discussion of social acceleration and the self suggests that the prevailing socio-temporal order may also play a role in determining the extent to which selfhood exists on stable grounds. On the one hand, social acceleration can be thought of as a 'destabilizing' force. This quality of social acceleration is especially revealed by two of the types of self that we have introduced in this article: the 'reflexive' self and the 'reinventive' self. These two selves highlight how social acceleration prompts 'unruly' and 'dislocating' bouts of change in a person's material and social surroundings. In social environments where social acceleration is a prominent force, there tends to be a contraction in the amount of time it usually takes for objects and social routines and expectations to become outmoded (Rosa, 2003, p. 7). Accordingly, this means that social acceleration can have a destabilizing effect on the self, as people living in a high-speed society are increasingly unable to rely on the constancy of frames and instead are challenged to encounter new ones.

However, social acceleration on the other hand also displays various stabilizing properties. As revealed by our discussion of the 'detached self' and the 'stationary' self, it is possible to some extent for people to become accustomed to the regularly of change and movement. This means that social acceleration might have the capacity to generate a type of frame of action, which is stabilizing since it is based on the consistency, and thus the expectation, of having to move between frames. Our account of social acceleration also stresses that the speeding up process is almost never a totalizing one, which our description of the 'decelerating self' illustrates. Because there are some things that seem to either escape or run counter to accelerative forces in any given society, this means that the self can also be 'anchored' to some extent on these counter-trends or accelerative limits.

These theoretical reflections, to be sure, are only preliminary and are merely suggestive of the importance of engaging the social psychological study of the self with the theory of social acceleration. Similarly, our more sociologically informed account of how social acceleration operates at the level of the self is also intended as an initial step towards a more in-depth understanding of how social acceleration has 'ramifications for the socially dominant forms of self-relation' (Rosa, 2013, p. 224). Although we propose that there are at least five types of self which can be associated with the social acceleration phenomenon, there may be others, and more detailed theoretical and empirical work should be undertaken to ascertain what these are and what they entail. Social acceleration is a deeply complex and multi-faceted phenomenon and this, as we have shown, is also reflected and refracted at the level of the self.

Eric L. Hsu

Hawke Research Institute

University of South Australia

GPO Box 2471, Adelaide, South Australia 5001, Australia

eric.hsu@unisa.edu.au (corresponding author) 
Anthony Elliott

Hawke Research Institute

University of South Australia

GPO Box 2471, Adelaide, South Australia 5001, Australia

anthony.elliott@unisa.edu.au

\section{NOTES}

1 This is not to discount the contributions of other social researchers, who have also developed novel and sophisticated theorizations of the social acceleration concept. The work of John Tomlinson (2007) for instance has provided a detailed cultural analysis of the way speed has been discursively framed in late-modern societies. David Harvey (1999) has also illuminated some of the spatial dimensions of social acceleration in his analysis of postmodernity. And so too has the 'dromological' work of Paul Virilio (2006) enhanced what we know about social acceleration by describing how it is phenomenologically experienced.

${ }^{2}$ Within sociology, the concept of self has been articulated in a multitude of ways. Peter Callero (2003, p. 116), for example, observes that recent scholarship relating to the issue of the self has been 'multi-disciplinary, methodologically eclectic, and generally postmodern in orientation' and has not been derived from previously influential theoretical approaches to the self such as symbolic interactionism. Steve Pile (1993) selfhood discusses how there are divergent approaches to the concept of the self within the field of geography. And David Morgan and Michael Schwalbe (1990) highlight some of the differences between sociological and psychological understandings of selfhood.

${ }^{3}$ Why it is necessary to understand the self as a 'social force' is because doing so helps to avoid social reductionism, which narrowly views the self as an effect of social structures instead of as an agentic entity in its own right (e.g. Stetsenko \& Arievitch, 2004).

4 This link between social acceleration and the social scientific study of time has been made by a number of recent works (Hassan, 2009; Hsu, 2011, 2014b; Tomlinson, 2007; Vostal, 2014). Rosa (2013, pp. 1-13) produces an especially detailed and nuanced discussion of how social acceleration relates to the sociology of time.

${ }^{5}$ This category of acceleration is 'paradoxical' because it seems logical to conclude that 'time should become abundant' if 'technological acceleration means that less time is needed' (2003, p. 9). However, Rosa intimates that the two forms may in some instances be mutually reinforcing, as the drive to live busier, more productive lifestyles is commonly linked to the speeding up of social processes.

${ }^{6}$ Accordingly, this is why it makes sense to say that social acceleration precipitates certain kinds of social changes, while also framing change as one of the key features of the acceleration process.

${ }^{7}$ Rosa (2013) argues that social acceleration is driven by a 'cultural motor', an 'economic motor', a 'socio-structural' motor, and by the State and military forces.

${ }^{8}$ For instance, clothing trends have been shown to change more frequently now than in previous eras (McAfee et al., 2004), as the proliferation of 'fast fashion' retailers indicates (e.g. Bruce \& Daly, 2006). Social acceleration is also thought to have transformed many aspects of the food industry. Not only is 'fast food' becoming more of a ubiquitous phenomenon (Ritzer, 2004), but also the way food is grown (Pollan, 2009), prepared and transported (Weis, 2007) has gotten faster.

9 Rosa (2005) provides a particularly nuanced account of how social acceleration relates to the modern growth and decline of democratic politics. He argues that although 
'the speed-up of society' has played an integral part in the democratization process, social acceleration also has the capacity 'to undermine the proper functioning of democracy', once it goes 'beyond a certain critical threshold' (2005, p. 446).

Paul Virilio (2006) focuses in particular on how the recent acceleration of warfare interferes with democratic processes. When speed, above all else, comes to determine the winners and losers of combat, Virilio suggests that this leads to reduction in the amount of time there is for humans to make decisions. And subsequently, this affects how much time there is for reflection and deliberation in the political realm (Tomlinson, 2007, p. 59; see also Rosa, 2013, pp. 195-207).

${ }^{10}$ The idea that speed is a key feature of the modern world is also found in the work of other prominent scholars of modernity. Peter Conrad, for example, posits that 'modernity is about the acceleration of time' (1999, p. 9), while Thomas Hylland Eriksen just simply states that 'modernity is speed' (2001, p. 159). Rosa (2013, pp. 46-55) details how the theme of acceleration is also present in the work of various classical sociological thinkers on the topic of modernity (see also Tomlinson, 2007, pp. 7-8).

${ }_{11}$ Modernity, from this vantage point, is about the advancement of a 'post-traditional' social order, which propels 'social life away from the hold of pre-established precepts or practices' (Giddens, 1991, p. 20).

${ }^{12}$ The notion that people may not be able to react competently to the demands of a high-speed society has been well developed in the field of politics. Scheuerman (2005), Levy (2006) and Rosa (2005) all posit that social acceleration makes it difficult to appropriately engage in democratic politics once the speed of a society exceeds a certain limit.

${ }_{13}$ Tomlinson uses the example of driving to illustrate this point. Although 'driving provides the most readily available opportunity for people to become the agents of their own independent speed and to experience the exhilaration of fast machines', 'it is probably the most intensely regulated and, literally, policed area of everyday life' (2007, p. 65).

${ }^{14}$ Rosa cites the metaphor of a traffic jam to illustrate this aspect of social deceleration. Traffic jams occur paradoxically 'as a consequence of everybody's resolve to move fast' through the use of motor vehicles (2010, p. 35). Traffic jams do not normally happen because of people's desire to move more slowly.

${ }_{15}$ This insight partly derives from Hsu's cultural analysis of slow food texts (2014a), which asserts that the slow food movement may not be as diametrically opposed to the social acceleration process as some suggest.

${ }^{16}$ By suggesting that the complexities of social acceleration are reflected and refracted at the level of the self, we also seek to advance a more sophisticated view of social acceleration that appreciates the dynamic interplay between the phenomenon's micro and macro dimensions. As we have emphasized a number of times throughout this article, the social structural realities of social acceleration may affect the types of self that are expressed in a given society. But equally, it is also important to consider how selfhood itself is kind of a social force (Owens, 2003, p. 210), so that the structural properties of social acceleration are determined to some extent by the types of self that people acquire and experience.

\section{REFERENCES}

Adams, M. (2003). The reflexive self and culture: a critique. The British Fournal of Sociology, 54(2), 221-238.

Agger, B. (2004). Speeding up fast capitalism. Boulder: Paradigm Publishers.

Agger, B., \& Shelton, B. A. (2007). Fast families, virtual children: a critical sociology of families and schooling. Boulder: Paradigm Publishers. 
Aho, K. (2007). Simmel on acceleration, boredom, and extreme aesthesia. Fournal for the Theory of Social Behaviour, 37(4), 447-462.

Allen, J., \& Hamnett, C. (1995). Introduction. In J. Allen \& C. Hamnett (Eds.), A shrinking world?: global unevenness and inequality (pp. 1-10). Oxford: Oxford University Press.

Bauman, Z. (2003). Liquid love: on the frailty of human bonds. Cambridge: Polity Press.

Baumeister, R. (Ed.). (1999). The self in social psychology. Philadelphia: Psychology Press.

Beck, U. (1994). The reinvention of politics: Towards a theory of reflexive modernization. In U. Beck, A. Giddens \& S. Lash (Eds.), Reflexive modernisation (pp. 1-55). Cambridge: Polity.

Bertman, S. (1998). Hyperculture: the human cost of speed. London: Praeger Publishers.

Bruce, M., \& Daly, L. (2006). Buyer behaviour for fast fashion. Journal of Fashion Marketing and Management, 10(3), 329-344.

Callero, P. (2003). The Sociology of the Self. Annual Review of Sociology, 29, 115133.

Chesneaux, J. (2000). Speed and democracy: an uneasy dialogue. Social Science Information, 39(3), 407-420.

Conrad, P. (1999). Modern times and modern places: how life and art were transformed in a century of revolution, innovation, and radical change. New York: Knopf.

Cordero, R. (1991). Managing for speed to avoid product obsolescence: A survey of techniques. Fournal of Product Innovation Management, 8(4), 283-294.

Crary, J. (2013). 24/7: late capitalism and the ends of sleep. London: Verso.

Cross, S., \& Gore, J. (2005). Cultural models of the self. In M. Leary \& J. Tangney (Eds.), Handbook of self and identity (pp. 536-564). New York: The Guildford Press.

Elliott, A. (2008). Making the cut: how cosmetic surgery is transforming our lives. London: Reaktion Books.

Elliott, A. (2013). Reinvention. New York: Routledge.

Elliott, A. (2014). Concepts of the self (3rd ed.). Cambridge: Polity Press.

Elliott, A., et al. (2012). The new individualism and contemporary Japan. Fournal for the Theory of Social Behaviour, 42(4), 425-443.

Eriksen, T. H. (2001). Tyranny of the moment. London: Pluto Press.

Erturk, I., \& Solari, S. (2007). Banks as continuous reinvention. New Political Economy, 12(3), 369-388.

Flaherty, M., \& Fine, G. (2001). Past, present and future: Conjugating George Herbert Mead's perspective on time. Time and Society, 10(2/3), 147-161.

Fukuyama, F. (1992). The end of history and the last man. New York: Free Press.

Gergen, K. (1991). The saturated self: dilemmas of identity in contemporary life. New York: Basic Books.

Giddens, A. (1990). The consequences of modernity. Stanford: Stanford University Press.

Giddens, A. (1991). Modernity and self-identity: self and society in the late modern age. Stanford: Stanford University Press.

Giddens, A. (1994). Living in a post-traditional society. In U. Beck, A. Giddens \& S. Lash (Eds.), Reflexive modernization (pp. 56-109). Cambridge: Polity.

Grossen, M., \& Salazar Orvig, A. (2011). Dialogism and dialogicality in the study of the self. Culture and Psychology, 17(4), 491-509.

Harvey, D. (1999). The condition of postmodernity. Oxford: Blackwell.

Hassan, R. (2009). Empires of speed: time and the acceleration of politics and society. Boston: Brill.

Hassan, R. (2010). Social acceleration and the network effect: a defence of social 'science fiction' and network determinism. The British Fournal of Sociology, 61(2), 356-374.

Heine, S. (2001). Self as cultural product: An examination of east asian and north American selves. Fournal of Personality, 6, 881-905. 
Heylighen, F. (1998). Technological acceleration. In F. Heylighen, G. Joslyn \& V. Turchin (Eds.), Principia Cybernetica Web. Retrieved from http://pespmcl.vub.ac.be/ TECACCEL.html.

Hsu, E. L. (2011). New identities, new individualism. In A. Elliott (Ed.), The Routledge handbook of identity Studies (pp. 129-148). London and New York: Routledge.

Hsu, E. L. (2014a). The slow food movement and time shortage: Beyond the dichotomy of fast or slow. Fournal of Sociology. Advance online publication. doi: 10.1177/ 1440783313518250.

Hsu, E. L. (2014b). The Sociology of Sleep and the Measure of Social Acceleration. Time and Society, 23(2), 212-234.

Hutton, W., \& Giddens, A. (2002). Preface. In W. Hutton \& A. Giddens (Eds.), On the edge: living with global capitalism (pp. vii-xi). London: Vintage.

Jensen, M. (2006). Environment, Mobility and the Acceleration of Time: A sociological analysis of transport flows in modern life. In G. Spaargaren, A. Mol \& F. Buttel (Eds.), Governing environmental flows: global challenges to social theory (pp. 327-350). Cambridge: MIT Press.

Jessop, B. (2005). The Future of the State in an Era of Globalization. In A. Pfaller \& M. Lerch (Eds.), Challenges of globalization: new trends in international politics and society (pp. 13-26). New Brunswick: Transaction Publishers.

Kavanagh, D., et al. (2007). Running to Stand Still: Late Modernity's Acceleration Fixation. Cultural Politics, 3(1), 95-122.

King, S., \& Cushman, D. (Eds.). (1994). High speed management and organizational communication in the 1990s: A Reader. Albany: State University of New York Press.

Levine, R. (1997). A geography of time. New York: Basic Books.

Levy, D. (2006). More, Faster, Better: Governance in an Age of Overload, Busyness, and Speed. First Monday, 7.

Lifton, R. (1999). The protean self: human resilience in an age of fragmentation. Chicago: University of Chicago Press.

Luttwak, E. (1999). Turbo-capitalism: winners and losers in the global economy. New York: HarperCollins.

McAfee, A., et al. (2004). Zara: IT for fast fashion. Cambridge: Harvard Business School Publishing.

McGrath, J., \& Kelly, J. (1986). Time and human interaction: toward a social psychology of time. New York: Guilford Press.

Melbin, M. (1987). Night as frontier: Colonizing the World After Dark. New York: Free Press.

Moore, H., et al. (2011). Moving between frames: The basis of the stable and dialogical self. Culture and Psychology, 17(4), 510-519.

Morgan, D., \& Schwalbe, M. (1990). Mind and Self in Society: Linking Social Structure and Social Cognition. Social Psychology Quarterly, 53(2), 148-164.

Nyseth, T. (2009). Place Reinvention at the Northern Rim. In T. Nyseth \& A. Viken (Eds.), Place reinvention: northern perspectives (pp. 1-14). Farnham: Ashgate.

Nyseth, T., \& Viken, A. (Eds.). (2009). Place reinvention: northern perspectives. Farnham: Ashgate.

Offe, C. (1987). The Utopia of the Zero-Option: Modernity and Modernization as Normative Political Criteria. Praxis International, 7(1), 1-24.

Owens, T. (2003). Self and Identity. In J. Delamater (Ed.), Handbook of social psychology (pp. 205-232). New York: Kluwer Academic/Plenum Publishers.

Parkins, W. (2004). Out of Time Fast Subjects and Slow Living. Time and Society, 13(2/3), 363-382.

Parkins, W., \& Craig, G. (2006). Slow living. Sydney: University of New South Wales Press. 
Pile, S. (1993). Human Agency and Human Geography Revisited: A Critique of 'New Models' of the Self. Transactions of the Institute of British Geographers, 18(1), 122-139.

Pollan, M. (2009). In defense of food: an eater's manifesto. New York: Penguin Press.

Ritzer, G. (2004). The McDonaldization of society. Thousand Oaks: Pine Forge Press.

Rosa, H. (2003). Social Acceleration: Ethical and Political Consequences of a Desynchronized High-Speed Society. Constellations, 10(1), 3-33.

Rosa, H. (2005). The Speed of Global Flows and the Pace of Democratic Politics. New Political Science, 27(4), 445-459.

Rosa, H. (2010a). Full speed burnout? From the pleasures of the motorcycle to the bleakness of the treadmill: the dual face of social acceleration. International Fournal of Motorcycle Studies, 6(1).

Rosa, H. (2010b). Alienation and acceleration: towards a critical theory of late-modern temporality. Malmo: NSU Press.

Rosa, H. (2013). Social acceleration: a theory of modernity. New York: Columbia University Press.

Rosa, H., \& Scheuerman, W. E. (2009). Introduction. In H. Rosa \& W. E. Scheuerman (Eds.), High speed society: social acceleration, power and modernity (pp. 1-29). University Park: The Pennsylvania State University Press.

Salgado, J., \& Goncalves, M. (2007). The dialogical self: Social, personal and (un)conscious. In J. Valsiner \& A. Rosa (Eds.), Cambridge handbook of sociocultural psychology (pp. 608-621). Cambridge: Cambridge University Press.

Savage, M. (2009). Against epochalism: An analysis of conceptions of change in British sociology. Cultural Sociology, 3(2), 217-238.

Scheuerman, W. E. (2004). Liberal democracy and the social acceleration of time. Baltimore: The Johns Hopkins University Press.

Scheuerman, W. E. (2005). Busyness and citizenship. Social Research: An International Quarterly, 72(2), 447-470

Schmitt, C. (2009). The motorized legislator. In H. Rosa \& W. E. Scheuerman (Eds.), High-speed society: social acceleration, power, and modernity (pp. 65-73). University Park: Pennsylvania State University Press.

Simmel, G. (2002). The metropolis and mental life. In G. Bridge \& S. Watson (Eds.), The Blackwell city reader (pp. 11-19). Oxford: Wiley-Blackwell.

Simmel, G. (2004). The philosophy of money. London: Routledge.

Simonsen, D. G. (2005). Accelerating modernity: time-space compression in the wake of the aeroplane. The Fournal of Transport History, 26(2), 98-117.

St. Clair, M. (2011). So much, so fast, so little time. Santa Barbara: Praeger.

Stetsenko, A., \& Arievitch, I. (2004). The self in cultural-historical activity theory. Theory and Psychology, 14(4), 475-503.

Szollos, A. (2009). Toward a psychology of chronic time pressure. Time and Society, 18(2/3), $332-350$.

Tam, D. (2008). Slow journeys: What does it mean to go slow? Food, Culture and Society, 11(2), 208-218.

Thiele, L. (1997). Postmodernity and routinization of novelty. Polity, 29(4), 1-30.

Thrift, N. (2006). Re-inventing invention: new tendencies in capitalist commodification. Economy and Society, 35(2), 279-306.

Thrift, N. (2008). A perfect innovation engine: The rise of the talent world. Distinktion: Scandinavian Fournal of Social Theory, 9(1), 115-140.

Toffler, A. (1970). Future shock. New York: Bantam Books.

Tomlinson, J. (2007). The culture of speed: the coming of immediacy. London: Sage Publications.

Turkle, S. (2008). Always-on/always-on-you: The tethered self. In J. Katz (Ed.), Handbook of mobile communication studies (pp. 121-138). Cambridge: MIT Press. 
Virilio, P. (2006). Speed and politics. Los Angeles: Semiotext(e).

Vostal, F. (2014). Thematizing speed; Between critical theory and cultural analysis. European Fournal of Social Theory, 17(1), 95-114.

Wajcman, J. (2008). Life in the fast lane? Towards a sociology of technology and time. The British Fournal of Sociology, 59(1), 59-77.

Weis, T. (2007). The global food economy: the battle for the future of farming. London: Zed Books. Williams, S. J. (2005). Sleep and society. London: Routledge.

Williams, S. J. (2011). The politics of sleep: governing (un)consciousness in the late modern age. New York: Palgrave Macmillan. 